\title{
The Effects of Exercise Preferences on Body Fat and Body Mass Index by Self-report
}

\author{
Sema Can ${ }^{1, *}$, Erkan Demirkan ${ }^{1}$, Serkan Ercan $^{2}$ \\ ${ }^{1}$ Faculty of Sports Sciences, Hitit University, Turkey \\ ${ }^{2}$ Institute of Health Sciences, Hitit University, Turkey
}

Copyright $\bigcirc 2019$ by authors, all rights reserved. Authors agree that this article remains permanently open access under the terms of the Creative Commons Attribution License 4.0 International License

\begin{abstract}
Body fat (BF) and body mass index (BMI) that including physical fitness with health is important to protect and improve to the health. The aim of this study is to examine the effects of exercise preferences on BMI, body fat according to by self-report. A total of 442 volunteers, including 180 female and 262 male participated in the study. Body weight, height, BF and exercise preferences of participants who were members of the physical activity center were obtained according to their self-reports. Body fat analysis was determined by the BIA method (Tanita SC 330). In the analysis of the data, in addition to frequency and percentage values, independent t-test was used to compare between the genders and paired t-test was used for pre and post study in genders. Aerobic exercises affected in male body weight, BMI and BF $(p<0.05)$, in strength exercises only BF affected $(p<0.05)$, in combined exercises it was found that both genders significantly affected on all variables $(p<0.05)$. As a conclusion, combine exercises in both of gender, compared with only aerobic and strength, was found that have a more positive effect on body mass index and body fat.
\end{abstract}

Keywords Body Fat, Body Mass Index, Exercise

\section{Introduction}

It is known that physically active life is important in health protection and development. Body composition within physical fitness elements is important in obesity classification, nutrition level, evaluation of gains as a result of exercise, protection and development of general health [1]. In many national and international researches, regular physical activity or exercise has been reported to improve body weight control and body composition, thereby reducing chronic disease prevalence $[2,3,4]$. Body composition can be examined in two sections as fat mass and fat free mass. Fat-free mass contains muscle, bone, water, nerves, veins and organic structures, fat mass contains subcutaneous fat, storage fat, and essential fats. The evaluation of body fat level as a percentage gives information about the general health status of individuals. In mid-age adult male (30-39 years), the optimal body fat percentage is reported to be $12-22 \%$ and in female it is 16 - 26\% [5]. The percentage of body fat in male over $25 \%$ and body fat percentage in female over $32 \%$ constitute a health risk, while the minimum level is accepted as $8 \%$ to $12 \%$ for female and $5 \%$ for male [6]. Organizations such as Center for Disease Control and Prevention (CDC), the American College of Sport Medicine (ACSM) and the World Health Organization (WHO) offer physical activity for healthy living [2]. Physical activity, exercise and sports are used as interchangeable concepts. However, physical activity is defined as "body movements that result in energy expenditure resulting from contraction of skeletal muscles" [7]. Exercise is defined as regular and planned activities that take into account some of the physical fitness elements (aerobic fitness, muscular fitness, body composition, etc.) for a target. The planned and regular exercise can bring about changes on the body. For example, aerobic exercises may have a positive effect on insulin sensitivity and glucose homeostasis as well as on some cardiovascular risk factors such as hypertension, dyslipidemia and fibrinolytic activity [2,3,8]. Resistance exercises are the most popular strength working practices of physical exercises for strength and muscle mass increase. The effects of resistance exercises after adaptation include general health level, body composition and performance enhancing improvement [9]. In order to achieve the desired health benefit, it is emphasized that an activity should be done in a certain frequency and duration when making these recommendations. At least 5 days per week, 30 minutes (min) moderate or at least 3 days $20 \mathrm{~min}$ with strong aerobic activity and at least 2 days of strength activities should be done [10]. In this respect, the aim of this study is to investigate the effects of aerobic, strength and combined exercise preferences on the body fat and body mass index of the individuals who regularly attend the fitness center for certain purposes. 


\section{Materials and Methods}

\subsection{Subjects}

A total of 442 volunteers, 180 female $\left(\mathrm{M}_{\text {age }} \overline{\mathrm{x}}=34.40 \pm\right.$ $10.15)$ and 262 male $\left(\mathrm{M}_{\text {age }}=32.95 \pm 9.38\right)$, who were members of the physical activity center, were included in this study. The participants were evaluated in 3 groups as aerobic, strength and combined exercise considering their exercise preferences. Aerobic/exercise group was constituted by those engaging in walking/jogging/running, swimming, spinning and cycling; strength exercises group by those engaging in free-machine based weight exercises, pilates and crossfit and combined exercise group by those who prefer both strength and aerobic exercises. Prior to this study, ethics committee approval was obtained from the Hitit University Non-Invasive Research Ethics Committee (Decision no: 2018-111).

\subsection{Data Collection Tools}

The personal information form prepared by the researchers and the questions developed from the sports / exercise activities section of the Physical Activity Assessment Questionnaire (PAAQ) were used to obtain the data [11]. Body composition analyzes of the participants who were members of the physical activity center were determined by the BIA method in the center. Their body weight, height, body fat percentage and exercise preferences were obtained based on their reports. BMI was obtained with $\mathrm{kg}$ / (height $\mathrm{x}$ height) formula.

\subsection{Statistical Analysis}

In the analysis of the data, mean, standard deviation, frequency (f) and percentage (\%) values are given. The normality test of the data was determined by the Shapiro-Wilk test. Independent t-test was used to compare between the genders and paired t-test was used for pre and post study in genders. All statistical analyzes were made in SPSS package program (version 23.0) and the significance level was taken as 0.05 .

\section{Results}

In the presentation of the data obtained as a result of the study, Table 1 presents the descriptive characteristics of the participants. Table 2 presents according to gender exercises preferences in female; walking/running, swimming, strength and pilates, spinning, bike, crossfit respectively; in male, strength, pilates, swimming, walking/running, spinning, bike, crossfit respectively. There is only a significant differences in strength exercises type both the duration and frequency between the genders $(\mathrm{p}<0.001)$. Table 3 presents the body weight, body fat and body mass index changes according to the exercise preferences of the participants. In male, there was only a significant decreases of body weight, BMI, body fat in aerobic exercises $(p<0.05)$, in strength exercises there was only a significant decreases body fat $(\mathrm{p}<0.05)$. In combine exercises was also seen to a significant decreases in body weight, BMI, body fat in both male and female $(\mathrm{p}<0.05)$.

Age, height, body weight and BMI values of male and female by gender are shown as mean and minimum-maximum in Table 1.

Table 1. The Descriptive Characteristics of the Participants

\begin{tabular}{llll}
\hline Variables & Mean \pm SD & Minimum & Maximum \\
\hline Female (n=180) & $34.40 \pm 10.15$ & 16 & 66 \\
\hline Age (year) & $164.31 \pm 6.75$ & 135 & 180 \\
\hline Height (cm) & $64.66 \pm 10.90$ & 40 & 110 \\
\hline Body weight (kg) & $24.00 \pm 4.16$ & 16.96 & 40.90 \\
\hline BMI & & 16 & 75 \\
\hline Male (n=262) & $32.95 \pm 9.38$ & 162 & 198 \\
\hline Age (year) & $177.71 \pm 6.41$ & 57 & 120 \\
\hline Height (cm) & $82.32 \pm 10.68$ & 19.38 & 36.68 \\
\hline Body weight (kg) & $26.03 \pm 2.96$ & & \\
\hline BMI & & & \\
\hline
\end{tabular}

BMI: Body mass index; SD: Standard deviation 
Table 2. The Participants' Exercise Preferences by Self-reports

\begin{tabular}{|c|c|c|c|c|c|c|c|c|c|}
\hline \multirow{2}{*}{$\begin{array}{l}\text { Exercise } \\
\text { Type }\end{array}$} & \multirow{2}{*}{ Group } & \multicolumn{2}{|c|}{ Type } & \multicolumn{2}{|c|}{ Duration (min/day) } & \multicolumn{4}{|c|}{ Frequency (day/week) } \\
\hline & & $\begin{array}{c}\text { Female } \\
\text { f }(\%)\end{array}$ & $\begin{array}{l}\text { Male } \\
\text { f }(\%)\end{array}$ & $\begin{array}{c}\text { Female }^{\mathrm{a}} \\
\text { Mean } \pm \text { SD }\end{array}$ & $\begin{array}{c}\text { Male }^{\mathrm{b}} \\
\text { Mean } \pm \text { SD }\end{array}$ & $\mathrm{p}^{(\mathrm{a}-\mathrm{b})}$ & $\begin{array}{c}\text { Female }^{\mathrm{a}} \\
\text { Mean } \pm \text { SD }\end{array}$ & $\begin{array}{c}\text { Male }^{\mathrm{b}} \\
\text { Mean } \pm \text { SD }\end{array}$ & $\mathrm{p}^{(\mathrm{a}-\mathrm{b})}$ \\
\hline \multirow{2}{*}{$\begin{array}{l}\text { Walking/ } \\
\text { Running }\end{array}$} & 1 & $128(29)$ & $156(35.3)$ & $26.2 \pm 14.6$ & $24.6 \pm 17.1$ & \multirow{2}{*}{ NS } & $3.37 \pm 1.48$ & $3.15 \pm 1.30$ & \multirow{2}{*}{ NS } \\
\hline & 2 & $52(11.8)$ & $106(24.0)$ & - & - & & - & - & \\
\hline \multirow{2}{*}{ Strength } & 1 & $93(21)$ & $215(48.6)$ & $37.4 \pm 21.3$ & $61.5 \pm 31.9$ & \multirow[b]{2}{*}{$.001 *$} & $3.02 \pm 1.2$ & $3.56 \pm 1.17$ & \multirow{2}{*}{$.001^{*}$} \\
\hline & 2 & $87(19.7)$ & $47(10.6)$ & - & - & & - & - & \\
\hline \multirow{2}{*}{ Pilates } & 1 & $93(21)$ & $16(3.6)$ & $40.4 \pm 11.0$ & $36.3 \pm 15.0$ & \multirow{2}{*}{ NS } & $2.09 \pm 0.9$ & $1.72 \pm 1.0$ & \multirow{2}{*}{ NS } \\
\hline & 2 & $87(19.7)$ & $246(55.7)$ & - & - & & - & - & \\
\hline \multirow{2}{*}{ Crossfit } & 1 & $24(5.4)$ & $43(9.7)$ & $32.8 \pm 19.8$ & $34.4 \pm 16.5$ & \multirow{2}{*}{ NS } & $1.47 \pm 0.8$ & $1.97 \pm 1.0$ & \multirow{2}{*}{ NS } \\
\hline & 2 & $156(35.3)$ & $219(49.5)$ & - & - & & - & - & \\
\hline \multirow{2}{*}{ Swimming } & 1 & $116(26.2)$ & $169(38.2)$ & $36.9 \pm 22.2$ & $40.1 \pm 26.2$ & \multirow{2}{*}{ NS } & $2.26 \pm 1.13$ & $2.54 \pm 1.30$ & \multirow{2}{*}{ NS } \\
\hline & 2 & $64(14.5)$ & $93(21.0)$ & - & - & & - & - & \\
\hline \multirow{2}{*}{ Spinning } & 1 & $81(18.3)$ & $66(14.9)$ & $43.6 \pm 7.25$ & $39.1 \pm 30$ & \multirow{2}{*}{ NS } & $1.93 \pm 0.9$ & $2.08 \pm 1.0$ & \multirow{2}{*}{ NS } \\
\hline & 2 & $99(22.4)$ & $196(44.3)$ & - & - & & - & - & \\
\hline \multirow{2}{*}{ Bike } & 1 & $45(10.2)$ & $47(10.6)$ & $19.0 \pm 13.1$ & $27.1 \pm 28.3$ & \multirow{2}{*}{ NS } & $2.51 \pm 1.20$ & $2.45 \pm 1.46$ & \multirow{2}{*}{ NS } \\
\hline & 2 & $135(30.5)$ & $215(48.6)$ & - & - & & - & - & \\
\hline
\end{tabular}

*p<0.05; Min: Minute; NS: Non significant; SD: Standard deviation; Group 1: The subjects participated in this kind of exercise; 2 : The subjects non-participated in this kind of exercise.

Table 3. The Body Weight, Body Fat and Body Mass Index According to the Exercise Preferences of the Participants.

\begin{tabular}{|c|c|c|c|c|c|c|c|c|c|}
\hline Exercise type & & Fer & & & & & & & \\
\hline \multirow{4}{*}{ Aerobic } & Variables & $\begin{array}{c}\text { Before } \\
\text { Mean } \pm \text { SD }\end{array}$ & $\begin{array}{c}\text { After } \\
\text { Mean } \pm \text { SD }\end{array}$ & (month) & $\mathrm{p}$ & $\begin{array}{c}\text { Before } \\
\text { Mean } \pm \text { SD }\end{array}$ & $\begin{array}{c}\text { After } \\
\text { Mean } \pm \text { SD }\end{array}$ & (month) & $\mathrm{p}$ \\
\hline & Body weight $(\mathrm{kg})$ & $68.58 \pm 12.19$ & $68.70 \pm 12.06$ & \multirow{3}{*}{$3.0 \pm 1.9$} & .869 & $85.10 \pm 8.60$ & $83.31 \pm 7.13$ & \multirow{3}{*}{$3.7 \pm 2.4$} & $.039 *$ \\
\hline & BMI & $25.72 \pm 4.94$ & $25.74 \pm 4.83$ & & .889 & $27.12 \pm 2.79$ & $26.53 \pm 2.05$ & & $.03 *$ \\
\hline & BF (\%) & $32.46 \pm 8.25$ & $32.51 \pm 9.24$ & & .925 & $23.76 \pm 3.88$ & $22.25 \pm 4.37$ & & $.022 *$ \\
\hline \multirow{3}{*}{ Strength } & Body weight $(\mathrm{kg})$ & $61.45 \pm 9.36$ & $62.20 \pm 9.27$ & \multirow{3}{*}{$6.8 \pm 4.2$} & .431 & $78.61 \pm 10.85$ & $77.85 \pm 8.24$ & \multirow{3}{*}{$3.9 \pm 2.3$} & .554 \\
\hline & BMI & $23.38 \pm 4.20$ & $23.68 \pm 4.34$ & & .392 & $25.00 \pm 2.97$ & $24.78 \pm 2.18$ & & .562 \\
\hline & BF (\%) & $27.33 \pm 11.37$ & $26.33 \pm 11.15$ & & .225 & $16.90 \pm 4.63$ & $15.90 \pm 4.20$ & & $.042 *$ \\
\hline \multirow{3}{*}{ Combined } & Body weight $(\mathrm{kg})$ & $64.72 \pm 12.07$ & $63.38 \pm 10.81$ & \multirow{3}{*}{$3.3 \pm 2.4$} & $.001 *$ & $83.90 \pm 12.99$ & $82.70 \pm 11.20$ & \multirow{3}{*}{$4.8 \pm 4.7$} & $.001 *$ \\
\hline & BMI & $24.00 \pm 4.38$ & $23.51 \pm 4.01$ & & $.001^{*}$ & $26.41 \pm 3.71$ & $26.03 \pm 3.08$ & & $.001 *$ \\
\hline & BF (\%) & $27.03 \pm 8.33$ & $25.37 \pm 7.95$ & & $.001 *$ & $20.60 \pm 7.26$ & $18.55 \pm 6.15$ & & $.001 *$ \\
\hline
\end{tabular}

*p<0.05; BF: Body fat; BMI: Body mass index; SD: Standard deviation 


\section{Discussion}

The aim of this study is to investigate the effects of different exercise types on body fat and body mass index in individuals who have aerobic, strength and combined exercise. According to WHO physical activity suggestions, it recommends 3 days/week and as an exercise duration $150 \mathrm{~min} /$ week for the healthy life. Many factors, especially gender and age, may affect the type, frequency and duration of exercise [12,13]. Fast walking, which is one of the moderate activities, is one of the most recommended activities to increase the level of physical activity. The findings of this study were examined according to percentage ratios, it was observed that in the first three types of activity with most highest participation, $29 \%$ of the female preferred walking/running, $26.2 \%$ preferred swimming and $21 \%$ preferred strength and pilates exercises and for male participants this ratio was $48.6 \%$ strength, $38.2 \%$ swimming and $35.3 \%$ walking/running (Table 2). These ratios show that most of the female prefer walking and running exercises and male prefer strength exercises. When the duration of participation according to exercise preferences is examined, it is seen that female spend the most exercise duration with 43.6 min of spinning exercise and male spend $61.5 \mathrm{~min}$ with strength exercises (Table 2). According to exercise preferences, when weekly exercise frequencies were examined, it was seen that walking, running and strength exercises are preferred in both genders with an average of 3 days (Table 2). The finding of the study is seen to be similar with WHO suggestions. The other findings of this study, it was seen that female prefer aerobic (walking, running, swimming, spinning) and pilates exercises. When exercise preference, duration and frequency were evaluated according to gender, 1t was seen that male prefered aerobic (walking, running, swimming) and strength exercises. In the literature studies, Karaca [14] stated that female prefer moderate activity $(<6$ MET / hour) and male prefer high intensity ( $\geq 6$ MET / hour) activities more. In addition, he emphasized that the most preferred type of exercise in both genders was walking. Şahin et al. [15], in another study where they investigated the exercise preferences of female, they stated that they preferred $62.1 \%$ walking, $22.4 \%$ aerobic-step, and $15.5 \%$ other physical activity types. In their study in which they asked the participants about their exercise preferences, Giles-Corti and Donovan [16] reported that 47.8\% preferred intense physical activity, $52.5 \%$ preferred mild to moderate physical activity, and $82.5 \%$ preferred walking activity. Karaca [14] stated that walking is the most preferred exercise because it has low risk of injury and it doesn't require any costs except for having a suitable sportswear. As exercising period, Ertaş [17] states that the exercise duration spent by the participants during the exercise is $45.43 \pm 270 \mathrm{~min}$ for male and $28.70 \pm 12.25 \mathrm{~min}$ for female. When the results of this study and literature are examined, it is observed that female mostly prefer aerobic exercises and male prefer aerobic and strength exercises.

When the findings of body fat changes were examined, it was found that there was a significant decrease in $\mathrm{BF}$ values of female only in combined exercises, and a significant decrease in all three types (aerobic, strength and combined) exercises in male (Table 3). In addition it was seen that the BF of male that participated strength exercises was about $15.9 \%$ and it was $22.2 \%$ and $18.5 \%$ for those participating aerobic and combined exercises respectively (Table 3).

When BF of female were examined, it was observed that the lowest BF (26.3\%, 25.3\% respectively) was in female doing strength and combined exercises while those who preferred aerobic exercise had a higher level of BF (32.5\%). These results indicate that those participants who do only aerobic exercise have higher levels of BF compared to strength and combined exercises. In comparing strength exercise duration and frequency in a week for both of gender, the study results show that the male preferred strength exercises as both exercise duration and frequency more than female (Table 2). In general, it was accepted that aerobic exercises increased the body weight and fat mass loss by causing more energy expenditure compared to the strength exercises [18]. However, recent studies show that combined exercises do not only increase free-fat body mass, but also show more effective results in reducing fat mass and percentage $[19,20,21,22]$. It is stated that resistance exercises are the most effective method for increasing muscle mass only. However, the desired results from resistance exercises depend on many variables such as the type of exercise, intensity, number of repetitions, rest intervals between sets, duration and weekly frequency [23]. In addition, individuals who attend the fitness center on a regular basis should choose the appropriate exercises to achieve the desired physical fitness level.

\section{Conclusions}

According to exercise preferences, it can be said that female prefer aerobic exercises, while male prefer strength exercises. In addition, when the effect of exercise preferences on body fat is examined, it can be said that the $\mathrm{BF}$ values of both genders are in ideal intervals for those doing strength and combined exercises and those doing aerobic exercises have higher $\mathrm{BF}$ from the ideal interval. As a result, it is thought that the combined exercises will have a significant change on body fat and BMI compared to only aerobic or strength exercises.

\section{Limitations}

There are some of limitations in this study. The data was obtained according to base on subjects verbally and we did not consider the daily nutrition plan in subject. 


\section{Conflicts of Interest}

The authors declare no conflict of interest for this study.

\section{REFERENCES}

[1] Moon, J.R. (2013). Body composition in athletes and sports nutrition: an examination of the bio impedance analysis technique. Eur J Clin Nutr, 67 Suppl 1: S54-9.

[2] Haskell, W.L., Lee, I.M., Pate, R.R., Powell, K.E., Blair, S.N., Franklin, B.A.,... Bauman A. (2007). Physical activity and public health: updated recommendation for adults from the American College of Sports Medicine and the American Heart Association. Med Sci Sports Exerc, 39(8), 1423-1434.

[3] Garber, C.E., Blissmer, B., Deschenes, M.R., Franklin, B.A., Lamonte, M.J., Lee, I.M.,... Swain, D.P. (2011). American College of Sports Medicine position stand. Quantity and quality of exercise for developing and maintaining cardiorespiratory, musculoskeletal, and neuromotor fitness in apparently healthy adults: guidance for prescribing exercise. Med Sci Sports Exerc, 43(7), 1334-1359.

[4] Can, S., Arslan, E., Ersöz, G. (2014). Current Perspectives on Physical Activity Ankara Univ Spor Bil Fak, 12(1):1-10.

[5] Miller, D.K. Measurement by the physical educator why and how. Chapter 14: Anthropometry and body composition, p.195. 5. Education. Mc Graw Hill, 2006.

[6] Heyward, V.H., Stolarczyk, LM. Applied body composition assessment. Human kinetics, p. 43-55. 1996.

[7] Caspersen, C.J., Powell, K.E., Christenson, G.M. (1985). Physical activity, exercise, and physical fitness: definitions and distinctions for health-related research. Public Health Rep, 100(2), 126-131.

[8] Lucotti, P., Monti, L.D., Setola, E., Galluccio, E., Gatti, R., Bosi, E., Piatti, P. (2011). Aerobic and resistance training effects compared to aerobic training alone in obese type 2 diabetic patients on diet treatment. Diabetes Res Clin Pract, 94(3), 395-403.

[9] Kraemer, W.J., Ratamess, N.A., French, D.N. (2002). Resistance training for health and performance. Curr Sports Med Rep, 1(3), 165-171.

[10] World Health Organization (WHO). Global recommendations on physical activity for health. Geneva; Switzerland: World Health Organization, 2010.

[11] Karaca, A., Ergen E., Koruç, Z. (2000). The reliability of and the validity of the physical activity assessment questionnaire (PAAQ). Hacettepe J of Sport Sciences, 11(1), 17-28.

[12] Owen, N., Sparling, P. B., Healy, G. N., Dunstan, D. W., Matthews, C. E. (2010). Sedentary behavior: emerging evidence for a new health risk. Mayo Clinic proceedings, 85(12), 1138-41.

[13] Sitthipornvorakul, E., Janwantanakul, P.J., van der Beek, A. (2014). Correlation between pedometer and the Global Physical Activity Questionnaire on physical activity measurement in office workers. BMC Res Notes, 7:280.
[14] Karaca, A. (2008). An examination of moderate and vigorous physical activity in adults with regard to sex. Hacettepe J. of Sport Sciences, 19(1), 54-62.

[15] Şahin, G., Özer, K., Söğütçü, T., Bavlı, Ö., Serbes, Ş., Yurdakul, H.Ö., Dohman, Z., Gözaydın, G. (2014). Regular physical activity habits in female. SSTB, 10(4), 88-97.

[16] Giles-Corti, B., Donovan, R.J. (2002). The relative influence of individual, social and physical environment determinants of physical activity. Soc Sci Med, 54(12), 1793-1812.

[17] Ertaş, Dölek, B. (2017). Determination of exercise behaviors of healthy adult individuals over 18 years of age. Journal of Human Sciences, 14(2), 1924-1937.

[18] Church, T. (2011). Exercise in obesity, metabolic syndrome, and diabetes. Prog Cardiovasc Dis, 53(6), 412-418. doi: 10.1016/j.pcad.2011.03.013

[19] Maledonça, R. M., de Araújo Júnior, A. T., de Sousa, M., \& Fernandes, H. M. (2014). The effects of different exercise programmes on female body composition. Journal of human kinetics, 43, 67-78. doi:10.2478/hukin-2014-0091

[20] Rossi, F.E., Fortaleza, A.C., Neves, L.M., Buonani, C., Picolo, M.R., Diniz, T.A.,... Freitas Junior, I.F. (2016). Combined training (aerobic plus strength) potentiates a reduction in body fat but demonstrates no difference on the lipid profile in postmaleopausal female when compared with aerobic training with a similar training load. $J$ Strength Cond Res, 30(1), 226-234.

[21] Mohammadi, H.R., Khoshnam, M.S., Khoshnam, E. (2018). Effects of different modes of exercise training on body composition and risk factors for cardiovascular disease in middle-aged male. Int J Prev Med. 9:9.

[22] Arslan, E., Can, S., Demirkan, E. (2017). Effect of short-term aerobic and combinedtraining program on body composition, lipids profile and psychological health inpremaleopausal female. Science \& Sports, 32, 106-113.

[23] Figueiredo, V.C., de Salles, B.F., Trajano, G.S. (2018). Volume for muscle hypertrophy and health outcomes: the most effective variable in resistance training. Sports Med, 48(3), 499-505. 